\title{
LETTERS
}

\section{Successful treatment of genital ulcers with infliximab in Behçet's disease}

\author{
G Haugeberg, M Velken, V Johnsen
}

Ann Rheum Dis 2004;63:744-745. doi: 10.1136/ard.2003.010975

$\mathrm{R}$ ecurrent oral and genital aphthous ulcerations are the hallmarks of Behçet's disease. Up to now the various clinical manifestations in Behçet's disease have been treated with limited success. Recently, clinical observations have reported dramatic responses on clinical signs and symptoms in patients treated with tumour necrosis factor $\alpha$ $(\mathrm{TNF} \alpha)$ blocking drugs, including severe mucocutaneous, ${ }^{1-3}$ gastrointestinal ${ }^{45}$ and ocular manifestations. ${ }^{6}$

We report the successful treatment with infliximab of a severe longstanding genital ulcer in a patient with Behçet's disease.

\section{CASE REPORT}

The patient was a 29 year old woman with Behçet's disease who had had recurrent oral ulcers from age 5 and genital ulcers, arthralgia, and uveitis from age 23. The outbreaks of uveitis were treated with local administration of dexamethasone only. From autumn 2000 the severity of the genital manifestations increased, and treatment with colchicine and prednisolone was started. However, during follow up she still had painful recurrent oral and genital ulcers. In December 2001 she had a new outbreak of a severe genital ulcer located at the left labium majus. No sign of spontaneous improvement was seen, and high dose prednisolone treatment $(60 \mathrm{mg}$ a day) was started in spring 2002. In summer, partial remission on per oral corticosteroid treatment had been achieved, but the painful ulcer was still present. During the following months the genital ulcer deteriorated despite high dose prednisolone treatment (initially $60 \mathrm{mg}$, which had to be reduced to $40 \mathrm{mg}$ because of mental symptoms). In December 2002 treatment with azathioprine, $50 \mathrm{mg}$ twice a day, was started in addition to prednisolone $30 \mathrm{mg}$ daily. Treatment with azathioprine was stopped after 2 weeks because of a respiratory infection. Although non-selective immunosuppressive drugs-for example, thalidomide, azathioprine, and cyclosporin A, had not been tested sufficiently as monotherapy or in combination, we decided to treat her with infliximab, after full discussion and consent. This decision was judged justified owing to, firstly, the severe longstanding physical and psychological burden for the patient, secondly, to reports on successful treatment of genital ulcers with infliximab in Behçet's disease, ${ }^{1-3}$ and, thirdly, to lack of response to high dose long term prednisolone treatment. The infliximab dose $5 \mathrm{mg} / \mathrm{kg}$ body weight infusion was given on four occasions at baseline, and after 2, 6 , and 15 weeks. The fourth infusion, planned at 12 weeks' follow up, was postponed owing to sinusitis treated with penicillin. No other possible infliximab side effects occurred. During treatment her general well being and fatigue improved.

At the time of the first infusion the ulcer was deep and had a diameter of $19 \mathrm{~mm}$ (fig lA). After one infusion, at 2 weeks' follow up, a marked improvement was seen (fig 1B), and at 6 weeks' follow up, 4 weeks after the second infusion, only a scar of the ulcer was left (fig 1C). At 2 months' follow up after the fourth infusion the patient was still in remission.

\section{DISCUSSION}

Our case report supports the results of others, ${ }^{1-3}$ and shows that treatment with infliximab is effective in inducing remission of genital ulcers in patients with Behçet's disease.

Recently, preliminary results from a double blind, placebo controlled study were presented on the effect of etanercept, another TNF blocking drug, on mucocutaneous manifestations in Behçet's disease. ${ }^{7}$ In this 4 week study eight $(40 \%)$ of the 20 etanercept treated patients achieved clinical remission of mucocutaneous manifestations compared with one $(5 \%)$ patient in the 20 placebo treated patients. ${ }^{7}$ Interestingly, in the case by Estrach et al, ${ }^{3}$ the orogenital ulcerations in a patient with Behçet's disease responded dramatically to treatment with infliximab after failure of etanercept. This raises the interesting question as to whether there is a difference in the efficacy in Behçet's disease between etanercept (soluble receptor binding $\mathrm{TNF} \alpha$ and $-\beta$ ) and
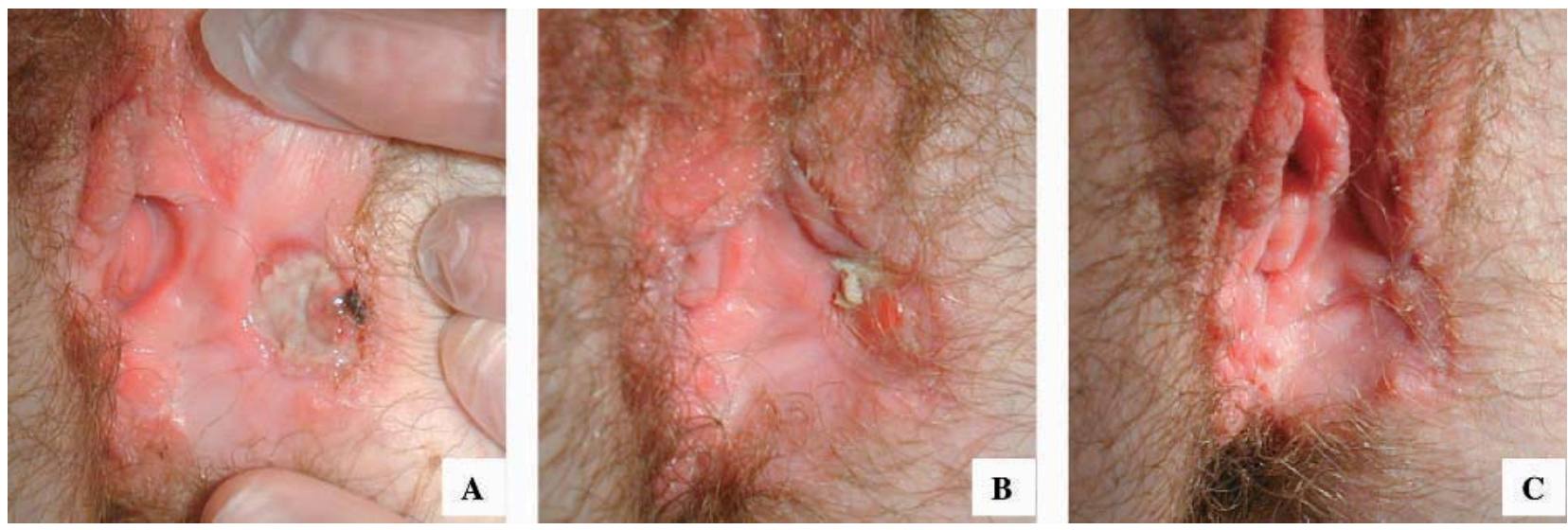

Figure 1 Active genital ulcer of the left labium majus together with genital scars. (A) Before the first infusion with infliximab; (B) 2 weeks after the first infusion; (C) 4 weeks after the second infusion. 
infliximab (monoclonal antibody binding TNF $\alpha$ ), drugs known to bind TNF $\alpha$ in different ways.

The experience so far with TNF $\alpha$ blocking treatment in Behçet's disease is scarce as recently reviewed by Sfikakis. ${ }^{8}$ So far, significant side effects with the use of TNF $\alpha$ blocking drugs in Behçet's disease have not been reported. ${ }^{8}$

Further clinical studies, especially double blind, randomised controlled trials designed with sufficient power are warranted before final conclusions can be drawn about the efficacy of treatment with TNF $\alpha$ blocking agents compared with conventional immunosuppressive agents.

\section{Authors' affiliations \\ G Haugeberg, V Johnsen, Department of Rheumatology, Sørlandet Hospital, Serviceboks 416, N-4604 Kristiansand S, Norway \\ M Velken, Department of Gynaecology, Sørlandet Hospital, Serviceboks 416, N-4604 Kristiansand S, Norway}

Correspondence to: Dr G Haugeberg, glennhaugeberg@operamail. com or glenn.haugeberg@sshf.no

Accepted 21 July 2003

\section{REFERENCES}

1 Goossens PH, Verburg RJ, Breedveld FC. Remission of Behçet's syndrome with tumour necrosis factor alpha blocking therapy. Ann Rheum Dis 2001;60:637.

2 Robertson LP, Hickling P. Treatment of recalcitrant orogenital ulceration of Behçet's syndrome with infliximab. Rheumatology (Oxford) 2001;40:473-4.

3 Estrach C, Mpofu S, Moots RJ. Behçet's syndrome: response to infliximab after failure of etanercept. Rheumatology (Oxford) 2002;41:1213-14.

4 Hassard PV, Binder SW, Nelson V, Vasiliauskas EA. Anti-tumor necrosis factor monoclonal antibody therapy for gastrointestinal Behçet's disease: a case report. Gastroenterology 2001;120:995-9.

5 Travis SP, Czajkowski M, McGovern DP, Watson RG, Bell AL. Treatment of intestinal Behçet's syndrome with chimeric tumour necrosis factor alpha antibody. Gut 2001;49:725-8.

6 Sfikakis PP, Theodossiadis PG, Katsiari CG, Kaklamanis P, Markomichelakis NN. Effect of infliximab on sight-threatening panuveitis in Behçet's disease. Lancet 2001;358:29-56.

7 Melikoglu M, Fresko I, Mat C, Ozyazgan Y, Yurdakul S, Hamuryudan V, et al. Etanercept is beneficial in controlling the mucocutaneous lesions of Behcet's syndrome (BS) at short term but does not suppress the pathergy reaction and the cutaneous response to intradermally injected monosodium urate (MSU) crystals: a double blind placebo controlled trial [abstract]. Arthritis Rheum 2002:46(suppl):S206

8 Sfikakis PP. Behçet's disease: a new target for anti-tumour necrosis factor treatment. Ann Rheum Dis 2002;61(suppl II):ii51-3.

\section{Lupus myocarditis in children}

\section{A Gupta, S Singh, R W Minz, B D Radotra, J Ahluwalia, A Grover}

C ardiovascular system (CVS) disease is the third leading cause of mortality in systemic lupus erythematosus (SLE). ${ }^{1}$ Pathologically it is pancarditis and may affect coronary arteries. ${ }^{23}$ Most often, it is subclinical. ${ }^{2-4}$ Clinical manifestations, if present, are limited to pericardial and endocardial involvement. ${ }^{2}$ Clinically apparent myocarditis has been described in a few adult patients. ${ }^{5-9}$ To the best of our knowledge, no such case has been described in children. We describe two children with clinically manifest myocarditis in SLE.

\section{CASE REPORTS}

A 12 year old girl, who was known to have had SLE for 2 months, presented with fever, malar rash, and photosensitivity. She had stopped taking steroids for 2 weeks. On examination, she had tachycardia with normal blood pressure. She had pallor, alopecia, oral ulcers, and malar rash. An examination of the CVS showed gallop rhythm with no murmurs. The rest of the systemic examination was unremarkable except for a tender hepatomegaly. Antinuclear factor (ANF) was strongly positive and anti-dsDNA titres were $198.2 \mathrm{IU} / \mathrm{ml}$ (normal $0-5 \mathrm{IU} / \mathrm{ml}$ ). Chest radiography showed cardiomegaly with normal lung fields. " $\mathrm{T}$ " wave changes were seen on electrocardiography. Creatine kinase levels were $220 \mathrm{U} / \mathrm{l}$ (normal 10-80 U/1). Echocardiography showed moderate mitral regurgitation, mild tricuspid regurgitation, and global hypokinesia with a left ventricular ejection fraction (LVEF) of 56\%. Pericardial effusion was minimal with no vegetations.

She recovered dramatically when given pulse methylprednisolone and decongestive treatment. Later, treatment was started with oral prednisolone at a dose of $2 \mathrm{mg} / \mathrm{kg} /$ day. Now 4 years later, she is asymptomatic with an LVEF of $72 \%$ on echocardiography.

The second patient, an 11 year old girl who was known to have had SLE for 6 months, presented with pain in the small joints, low grade fever, and cough for 1 month. She had stopped steroids on her own. On examination, she was shown to have generalised oedema, malar rash, and oral ulcers. She had tachycardia with normal blood pressure. Examination of the CVS showed a soft systolic murmur at the apex with normal heart sounds. She had hepatosplenomegaly. The rest of the systemic examination was unremarkable. Investigations showed normocytic, normochromic anaemia (haemoglobin $54 \mathrm{~g} / \mathrm{l}$ ) and deranged renal functions (blood urea nitrogen $26.5 \mathrm{mmol} / \mathrm{l}$, serum creatinine $220 \mu \mathrm{mol} / \mathrm{l}$ ). There was gross albuminuria, with urine microscopy showing red blood cells and casts. Chest radiography showed cardiomegaly with normal lung fields. Echocardiography showed moderate mitral regurgitation, trivial tricuspid regurgitation, and global hypokinesia with an LVEF of $18 \%$. No pericardial effusion or vegetations were present. ANF was strongly positive and anti-dsDNA titres were $1531 \mathrm{IU} / \mathrm{ml}$.

Treatment was started with pulse methylprednisolone. However, she developed cardiogenic shock on day 6 of admission. Pulse cyclophosphamide was started together with supportive treatment. She developed multiorgan dysfunction due to shock and died after 8 days in hospital. A necropsy showed diffuse proliferative glomerulonephritis, serositis, and myocarditis. Myocarditis was evident from the presence of focal collection of inflammatory cells with damage to adjacent myofibres, fibrinoid necrosis, and interstitial oedema. Fibrinous pericarditis was also seen, but the coronary arteries and valves were normal.

\section{DISCUSSION}

Myocardial dysfunction in SLE is multifactorial; important contributors are immune injury, coronary vasculitis, valvulopathy, hypertension, and adverse effects of drugs. ${ }^{3}$ Endomyocardial biopsy remains the preferred method for the diagnosis of myocarditis, but carries a high risk of mortality in sick children ${ }^{2}$ 
and was not carried out in our patients. In such a case, the presence of global hypokinesia with a low LVEF on echocardiography is a strong pointer towards the diagnosis. ${ }^{2}$ The diagnosis is even more definite in the second child as it was proved at necropsy. ${ }^{3}$ Lupus myocarditis has been associated with skeletal myositis $^{5}$ and anti-Ro and anti-La antibodies. ${ }^{4}$

Immunosuppressant drugs with decongestive agents remain the preferred treatment. ${ }^{23}$ Most patients respond dramatically. The second patient died despite immunosuppressive treatment and supportive care, probably because of delays in diagnosis and initiation of treatment. Finally, it is important to remember that acute myocarditis can be a fatal complication of SLE. Early diagnosis and prompt treatment may be very rewarding.

\section{Authors' affiliations \\ A Gupta, PGIMER, Chandigarh, India}

Correspondence to: Dr S Singh, surjitsingh@sify.com

Accepted 29 June 2003

\section{REFERENCES}

1 Doherty NE, Siegel RJ. Cardiovascular manifestations of systemic lupus erythematosus. Am Heart J 1985; 1 10:1257-65.

2 Ansari A, Larson PH, Bates HD. Cardiovascular manifestations of systemic lupus erythematosus: current perspective. Prog Cardiovasc Dis 1985;27:421-34

3 Wijetunga $M$, Rockson S. Myocarditis in systemic lupus erythematosus. Am J Med 2002;113:419-23.

4 Oshiro AC, Derbes SJ, Stopa AR, Gedalia A. Anti-Ro/SS-A and anti-La/SS-B antibodies associated with cardiac involvement in childhood systemic lupus erythematosus. Ann Rheum Dis 1997;56:272-4.

5 Borenstein DG, Fye WB, Arnett FC, Stevens MB. The myocarditis of systemic lupus erythematosus: association with myositis. Ann Intern Med 1978;89:619-24.

6 Dickens $\mathbf{P}$, Nicholls J, Lau CP. Acute hemorrhagic myocarditis in systemic lupus erythematosus. Heart Vessels 1992;7:104-6.

7 Sandrasegaran K, Clarke CW, Nagendran V. Subclinical systemic lupus erythematosus presenting with acute myocarditis. Postgrad Med J 1992;68:475-8.

8 Macro M, Le Gangneux E, Gallet E, Maragnes P, Galateau F, Loyau G. Severe lupus with infectious thyroiditis and lethal cardiomyopathy. Clin Exp Rheumatol 1995;13:99-102

9 Frustaci A, Gentiloni N, Caldarulo M. Acute myocarditis and left ventricular aneurysm as presentations of systemic lupus erythematosus. Chest 1996; 109:282-4

\title{
Dose escalation of leflunomide (LEF) to $40 \mathrm{mg}$ once daily in patients with rheumatoid arthritis and insufficient response to standard dose LEF
}

\author{
C Fiehn, E Rochel, A D Ho, R Max
}

Ann Rheum Dis 2004;63:746-747. doi: 10.1136/ard.2003.014217

eflunomide (LEF) is a new disease modifying antirheumatic drug (DMARD) for the treatment of rheumatoid - arthritis (RA) and it is recommended that it is given in a loading dose of $100 \mathrm{mg}$ over 3 days followed by a stable dose of $20 \mathrm{mg} /$ day. ${ }^{2}$ The dose of $20 \mathrm{mg} /$ day $\mathrm{LEF}$ was recommended because in an initial study which compared 5, 10, and $25 \mathrm{mg} /$ day LEF the highest dose tended to result in an increased rate of adverse events. ${ }^{3}$ However, in this study a clear dose-response relationship with best results in the $25 \mathrm{mg}$ /day group was observed as well. Therefore, the aim of this investigation was to evaluate whether patients who tolerate LEF in the standard dose of $20 \mathrm{mg} /$ day will tolerate a dose escalation of LEF to $40 \mathrm{mg} / \mathrm{day}$ and whether this improves the efficacy of the treatment.

\section{PATIENTS AND METHODS}

Eleven patients with RA were included in this prospective clinical investigation (table 1 ). All had received LEF in a dose of $20 \mathrm{mg} /$ day for at least 3 months without adverse effects, but still had active disease with a mean (SD) disease activity score (DAS28 ${ }^{4}$ ) of $4.9(0.6)$ (range 3.9-5.8). All of them had responded to the prior treatment with $20 \mathrm{mg}$ /day LEF, but either the response was not sufficient or the disease activity increased again despite continuous treatment.

To obtain better control of the disease the dose of LEF was increased from 20 to $40 \mathrm{mg}$ p.o. once daily. The patients were monitored by analysing the disease activity and the occurrence of adverse events after 2 months of treatment and after every subsequent 2 months for as long as the patient was receiving $40 \mathrm{mg} \mathrm{LEF}$.

\section{RESULTS}

Table 1 summarises the data obtained. After a mean (SD) follow up of 4.4 (3.7) months (range 0.5-11) 5 of 11 patients were still receiving treatment with $40 \mathrm{mg}$ /day LEF. Four patients had stopped treatment with LEF or reduced the dose to $20 \mathrm{mg} /$ day again because of adverse events: one patient with concomitant MTX treatment developed increased liver enzymes more than twice the normal values and stopped LEF 1.5 months after dose escalation. One patient who took concomitant rofecoxib reversed the dose escalation of LEF after 4 months because of glossitis, another patient after 2 weeks because of nausea and diarrhoea, and a third patient after 7 months because of abdominal pain of unknown origin. All adverse events were reversible after dose reduction of LEF. Six of 9 patients who were still receiving $40 \mathrm{mg}$ /day LEF after 2 months responded to the dose escalation of LEF: two had a good response (reduction of DAS28 >1.2 and inactive disease) and four had a moderate response (reduction of DAS28 from 0.6 to 1.2 or active disease despite reduction of DAS28 >1.2) as defined by van Gestel et al 1996. Two patients showed no change in disease activity. In all five patients who continued to receive LEF in a dose of $40 \mathrm{mg} /$ day, the response remained stable up to the last follow up.

\section{CONCLUSION}

In these preliminary findings the dose escalation of LEF to $40 \mathrm{mg} /$ day seems to increase the effectiveness of the treatment in a number of patients with RA. The adverse events of the dose escalation which appeared in four of 11 patients were 
Table 1 Characteristics of the patients with RA included in the study and effects of dose escalation of LEF from 20 to $40 \mathrm{mg}$ once daily on disease activity and the occurrence of adverse events. The response was calculated according to van Gestel 1996 et a ${ }^{4}$ after 2 months of treatment with $20 \mathrm{mg}$ LEF once daily. All adverse events were mild and reversible

\begin{tabular}{|c|c|c|c|c|c|c|c|c|c|c|}
\hline $\begin{array}{l}\text { Patient } \\
\text { No }\end{array}$ & $\begin{array}{l}\text { Age } \\
\text { (years), } \\
\text { sex }\end{array}$ & $\begin{array}{l}\text { DMARDs } \\
\text { (n) }\end{array}$ & $\begin{array}{l}\text { Years since } \\
\text { diagnosis }\end{array}$ & RF & Comedication & $\begin{array}{l}\text { DAS28 with } \\
\text { LEF20 before } \\
\text { LEF40 }\end{array}$ & $\begin{array}{l}\text { DAS28 at } \\
2 \text { months } \\
\text { LEF40 }\end{array}$ & $\begin{array}{l}\text { Maximum time on } \\
\text { LEF40 (months) }\end{array}$ & $\begin{array}{l}\text { Response after } \\
2 \text { months }\end{array}$ & Adverse events \\
\hline 1 & $44, F$ & 3 & 12 & + & Pred, MTX20 & 5.2 & 2.9 & 11 (continuing) & Good & - \\
\hline 2 & $46, \mathrm{~F}$ & 2 & 3 & + & Pred, rofecoxib & 3.9 & 3.8 & 4 & No change & Glossitis \\
\hline 3 & $67, \mathrm{~F}$ & - & 2 & + & Pred & 5.8 & 4.6 & 4 & Moderate & - \\
\hline 4 & $53, \mathrm{~F}$ & 2 & 6 & - & Pred, MTX20 & 4.7 & 3.5 & 7 & Moderate & Abdominal pain \\
\hline 5 & $66, F$ & 1 & 13 & + & Pred, & 4.8 & 3.9 & 3 (continuing) & Moderate & - \\
\hline 6 & $34, \mathrm{~F}$ & 4 & 9 & + & $\begin{array}{l}\text { Pred, MTX7.5, } \\
\text { diclofenac }\end{array}$ & 4.8 & NA & 1.5 & NA & Transaminases $\uparrow$ \\
\hline 7 & $45, \mathrm{~F}$ & 2 & 7 & + & - & 5.7 & NA & 0.5 & NA & $\begin{array}{l}\text { Nausea, } \\
\text { diarrhoea }\end{array}$ \\
\hline 8 & $48, M$ & 2 & 9 & + & Pred, SSZ & 4.4 & 4.0 & 11 & No change & - \\
\hline 9 & $21, \mathrm{~F}$ & 5 & 19 & - & Pred & 4.0 & 3.3 & 2 (continuing) & Moderate & - \\
\hline 10 & $62, F$ & - & 1 & + & Pred & 5.1 & 5.0 & 2 (continuing) & No change & - \\
\hline 11 & $50, \mathrm{~F}$ & 2 & 11 & - & Pred & 5.2 & 3.1 & 2 (continuing) & Good & - \\
\hline
\end{tabular}

DMARDs (n), number of DMARD treatments before the start of treatment with LEF; SSZ, sulfasalazine; MTX7.5, 7.5 mg methotrexate once weekly; MTX20, $20 \mathrm{mg}$ methotrexate once weekly; LEF20, leflunomide $20 \mathrm{mg} /$ day; LEF40, leflunomide $40 \mathrm{mg} /$ day; pred, prednisone or prednisolone; DAS28, disease activity score using the 28 tender joint count, the 28 swollen joint count, and the erythrocyte sedimentation rate.

mild and reversible. If confirmed in larger studies, the dose escalation of LEF might be especially valuable for patients with RA who tolerate LEF at the standard dose of $20 \mathrm{mg} /$ day but show insufficient response. For them the dose escalation might be a way to further improve disease activity and an alternative to an early switch to DMARD combination treatment or treatment with biological substances.

\section{Authors' affiliations}

C Fiehn, E Rochel, A D Ho, R Max, Department of Internal Medicine V, University of Heidelberg, Germany

Correspondence to: Dr C Fiehn, Centre for Rheumatic Diseases, BadenBaden, Rotenbachtalstr 5, 76530 Baden-Baden, Germany; c.fiehn@ rheumazentrum-baden.de

\section{REFERENCES}

1 Smolen JS, Kalden JR, Scott DL, Rozman B, Kvien TK, Larsen A, et al. Efficacy and safety of leflunomide compared with placebo and sulphasalazine in active rheumatoid arthritis: a double-blind, randomised, multicentre trial. European Leflunomide Study Group. Lancet 1999;353:259-66.

2 Cohen S, Cannon GW, Schiff M, Weaver A, Fox R, Olsen N, et al. Two-year, blinded, randomized, controlled trial of treatment of active rheumatoid arthritis with leflunomide compared with methotrexate. Utilization of Leflunomide in the Treatment of Rheumatoid Arthritis-Trial Investigator Group. Arthritis Rheum 2001:44:1984-92.

3 Mladenovic V, Domljan Z, Rozman B, Jajic I, Mihajlovic D, Dordevic J, et al. Safety and effectiveness of leflunomide in the treatment of patients with active rheumatoid arthritis. Results of a randomized, placebo-controlled, phase II study. Arthritis Rheum 1995;38:1595-603.

4 van Gestel AM, Prevoo ML, ' $\nmid$ Hof MA, van Rijswijk MH, van de Putte LB, van Riel PL. Development and validation of the European League Against Rheumatism response criteria for rheumatoid arthritis. Comparison with the preliminary American College of Rheumatology and the World Health Organization/International League Against Rheumatism Criteria. Arthritis Rheum 1996;39:34-40.

\section{Polyclonal immunoglobulins for intravenous use induce interleukin 10 release in vivo and in vitro}

\section{R J Lories, M Casteels-Van Daele, J L Ceuppens, S W Van Gool}

$\mathrm{P}$ lyclonal intravenous immunoglobulins (IVIg) are increasingly used in clinical practice, not only as substitutive agents but also in the treatment of immunologically mediated diseases. ${ }^{12}$ How IVIg modulate the immune system is not yet clear, but several immunoregulatory mechanisms have been postulated. ${ }^{2}$ We studied the production of the immunosuppressive cytokine interleukin $10 \quad(\mathrm{ILIO})^{3}$ as a potential explanation for the beneficiary effects of IVIg in autoimmune diseases.

IL10 concentrations were measured in six patients: one patient (aged 19) with X-linked agammaglobulinaemia, two patients (aged 63 and 64) with common variable immunodeficiency, one patient (aged 15) with hyper IgM syndrome, two patients (aged 4) with IgG2 subclass deficiency. All patients or their parents gave informed consent. Blood was collected before and immediately after infusion of IVIg (Sandoglobulin; Novartis, Brussels, Belgium), and ILl0 levels were measured with a sandwich enzyme linked immunosorbent assay (ELISA) technique (anti-IL10 Screening Line; Pharmingen, San Diego, CA). The serum IL10 levels were increased after infusion of IVIg in all six patients (Wilcoxon non-parametric test, $\mathrm{p}<0.01$ ) (fig $1 \mathrm{~A}$ ). No IL10 was detected in the IVIg.

Venous blood from healthy volunteers was collected and diluted 1:2 with culture medium. Final cell concentration was $1 \times 10^{4}$ white blood cells $/ \mathrm{ml}$. Cell culture was performed with or without endotoxin $(1 \mathrm{ng} / \mathrm{ml})$ or $\operatorname{IVIg}(3 \mathrm{mg} / \mathrm{ml})$ for 15 minutes to 24 hours. An increase in IL10 levels as early as 1 hour after incubation with IVIg was consistently seen in all experiments performed (fig 1B). IL10 levels reached their 

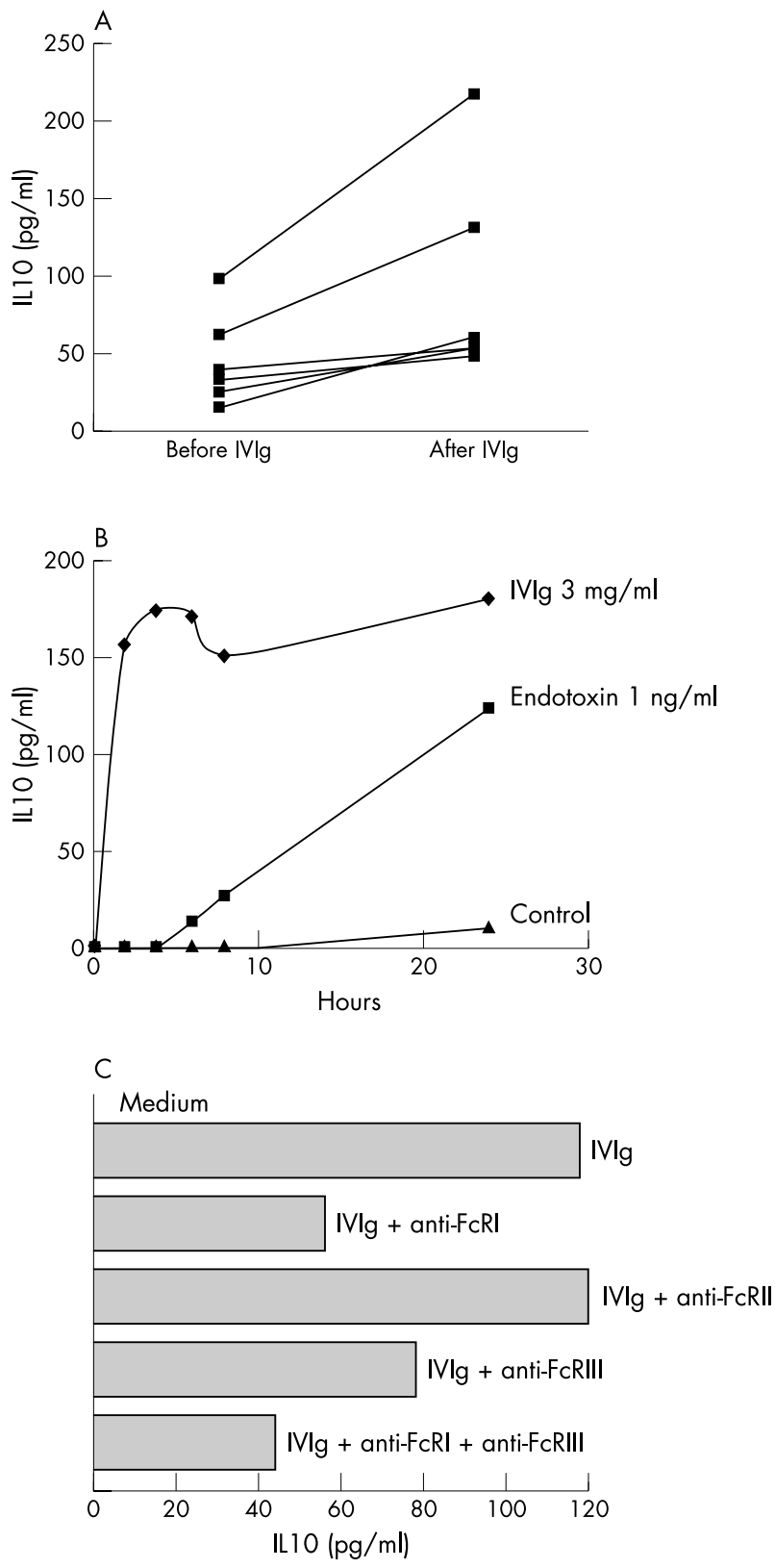

Figure 1 (A) Serum concentrations of interleukin 10 (IL10) are increased immediately after infusion of polyclonal immunoglobulins for intravenous use (IVlg) in immunodeficient patients; (B) IVlg rapidly and strongly increase IL 10 production in whole blood in vitro (one of seven experiments shown); (C) anti-FcR antibodies can inhibit IVlg induced IL10 production (one of three experiments shown).

highest level after 4 hours and remained high over the next 4 days. The rapid increase in ILI0 levels is remarkable because endotoxin induces IL10 only after 8 hours and induces levels comparable to IVIg only after 24 hours. Increases in IL10 were seen in all our experiments but varied in intensity between different donors.

We also studied the effect of IVIg on IL10 mRNA levels in peripheral blood mononuclear cells (PBMC) from healthy volunteers. $1 \times 10^{4}$ PBMC were stimulated with IVIg $(3 \mathrm{mg} / \mathrm{ml}$ ) in culture medium for 2 or 24 hours and IL10 mRNA content was determined using Taqman real time, quantitative, reverse transcriptase-polymerase chain reaction (Applied Biosystems, Lennik, Belgium; IL10 forward primer GTGATGCCCAAGCTGAGA, IL10 reverse primer CACGGCCTTGCTCTTGTTTT, IL10 probe CCAAGACCCAGACA-TCAAGGCGCA). Gene expression levels were normalised to the expression of the reference gene $\beta$-actin (ABI Prism Taqman Assay Reagents, Applied Biosystems). IVIg stimulation resulted in a mean 9.6-fold increase in IL10 mRNA levels after 24 hours, but not after 2 hours (data not shown). A rapid increase of ILl0 protein levels in vivo has previously been reported after liver transplantation. ${ }^{5}$ Our data further corroborate the hypothesis that IL10 production is regulated by both transcriptional and post-transcriptional mechanisms. ${ }^{3}$

In blocking experiments, cells were preincubated for 30 minutes in the presence of different anti-Fc $\gamma \mathrm{R}$ antibodies ${ }^{6}$ (anti-Fc $\gamma$ RI (197), anti-Fc $\gamma$ RII (IV.3), and anti-Fc $\gamma$ RIII (3G8), all from Medarex (Milpitas, CA)) at $10 \mathrm{ng} / \mathrm{ml}$ at $4^{\circ} \mathrm{C}$. IL10 production was effectively inhibited by monoclonal antibodies $(\mathrm{mAb})$ directed against the Fc $\gamma \mathrm{RI}$ and Fc $\gamma$ RIII. These mAb did not stimulate ILl0 production in controls. Anti-Fc $\gamma$ RI was responsible for the strongest inhibition, followed by anti-Fc $\gamma$ RIII. The combination of these mAbs was more effective in inhibiting IL10 production than either of the mAbs alone, showing that triggering of both receptors increases IL10 release independently. Remarkably, recent data suggest that immune complexes or sera from patients with systemic lupus erythematosus (SLE) trigger IL10 production from PBMC mainly through FCRII. ${ }^{4}$

IL10 is a potent anti-inflammatory cytokine regulating the production of monokines such as tumour necrosis factor $\alpha$ and ILl as well as shifting T cell responses towards a Th2 profile. Therefore, increased IL10 production by IVIg may provide an explanation for some of the remarkable immune suppressive properties in inflammatory and autoimmune diseases such as dermatomyositis. ${ }^{7}$

\section{ACKNOWLEDGEMENTS}

RJ Lories is the recipient of an "Aspirant" fellowship and SW Van Gool is a clinical research fellow of the Fund for Scientific Research, Flanders.

\section{Authors' affiliations}

R J Lories, Laboratory for Skeletal Development and Joint Disorders, Department of Rheumatology, University Hospitals Leuven, Katholieke Universiteit Leuven, Belgium

M Casteels-Van Daele, S W Van Gool, Department of Paediatrics, University Hospitals Leuven, Katholieke Universiteit Leuven, Belgium J L Ceuppens, S W Van Gool, Laboratory of Experimental Immunology, Department of Clinical Immunology, University Hospitals Leuven, Katholieke Universiteit Leuven, Belgium

Correspondence to: Professor Dr S Van Gool, Department of Paediatrics, University Hospitals Leuven, Herestraat 49, B-3000 Leuven, Belgium; Stefaan.Vangool@uz.kuleuven.ac.be

\section{Accepted 9 July 2003}

\section{REFERENCES}

1 Buckley RH, Schiff RI. The use of intravenous immune globulin in immunodeficiency diseases. N Engl J Med 1991;325:110-17.

2 Dwyer JM. Manipulating the immune system with immune globulin. N Engl J Med 1992;326:107-16.

3 Moore KW, de Waal MR, Coffman RL, O'Garra A. Interleukin-10 and the interleukin-10 receptor. Annu Rev Immunol $2001 ; 19: 683-765$.

4 Ronnelid J, Tejde A, Mathsson L, Nilsson-Ekdahl K, Nilsson B. Immune complexes from SLE sera induce IL10 production from normal peripheral blood mononuclear cells by an Fc $\gamma$ Rll dependent mechanism: implications for a possible vicious cycle maintaining B cell hyperactivity in SLE. Ann Rheum Dis 2003;62:37-42.

5 Le Moine O, Marchant A, Durand F, Ickx B, Pradier O, Belghiti J, et al. Systemic release of interleukin-10 during orthotopic liver transplantation. Hepatology 1994;20:889-92.

6 Heijnen IA, van de Winkel JG. Human IgG Fc receptors. Int Rev Immunol 1997; 16:29-55.

7 Dalakas MC, Illa I, Dambrosia JM, Soueidan SA, Stein DP, Otero C, et al. A controlled trial of high-dose intravenous immune globulin infusions as treatment for dermatomyositis. N Engl J Med 1993;329:1993-2000. 


\title{
Cevimeline gargle for the treatment of xerostomia in patients with Sjögren's syndrome
}

\author{
Y Takagi, Y Kimura, T Nakamura
}

Ann Rheum Dis 2004;63:749. doi: 10.1136/ard.2003.012633

1

rrigation of the salivary gland using a corticosteroid is one

of the most successful approaches to improving xerostomia

in patients with Sjögren's syndrome, yielding longlasting effects associated with minimal side effects. ${ }^{1}$ However, the treatment procedures are complicated, and the extent of improvement in salivary function is inversely related to the clinical severity of the disease, with the patients with most advanced disease not responding to the treatment.

Recently, cevimeline hydrochloride hydrate (Evoxac or Saligren) has been clinically applied to patients with Sjögren's syndrome for the treatment of xerostomia. ${ }^{2}$ Oral doses of cevimeline significantly improved subjective symptoms of dry mouth and dry eyes, and increased salivary flow. However, adverse effects were frequently reported, such as nausea and abdominal pain. Unless properly managed, these adverse effects would negatively affect the continued administration of cevimeline.

To overcome these disadvantages of oral doses of cevimeline, we evaluated the efficacy of cevimeline gargle for the treatment of xerostomia in patients with Sjögren's syndrome. We first evaluated the effect of the gargle in 11 healthy female volunteers (mean (SD) age 39 (13) years, range 1957), after approval from the ethical committee of our hospital. The volunteers were asked to gargle three times a day before meals using $30 \mathrm{mg}$ cevimeline dissolved in $100 \mathrm{ml}$ of water for each session. The effects of treatment were evaluated daily by a Saxon test performed at around $300 \mathrm{pm}$. Most of the healthy subjects responded well to the cevimeline gargle, and the salivary flow rate gradually increased, reaching an $81 \%$ increase on average by day 5 . Some subjects showed more than twofold increases in salivary flow after cevimeline gargle. No adverse effect was seen. Simple gargles without cevimeline had no effect.

Given the satisfactory efficacy and safety of the cevimeline gargle in healthy subjects, we next tested whether the same treatment was effective in patients with Sjögren's syndrome.
These patients fulfilled the criteria proposed by Fox et $a l^{3}$ and were also refractory to corticosteroid irrigation (table 1). Cevimeline gargle markedly increased salivary flow rates in two of the five patients. However, in the remaining three patients the effect of treatment was negligible. In three of these five patients clinical symptoms improved subjectively. No adverse effects were seen.

The exact mechanism of salivary flow stimulation by cevimeline gargle is not clear. Possibly, cevimeline binds directly to the muscarinic receptors of the minor salivary gland acini that communicate with the oral cavity. The observed inconsistency in treatment effects in the patients with Sjögren's syndrome may be due to severely damaged salivary acini. Further studies are necessary to evaluate cevimeline gargle treatment in a large cohort including more mildly affected patients.

\section{Authors' affiliations}

Y Takagi, Y Kimura, T Nakamura, Department of Radiology and Cancer Biology, Nagasaki University School of Dentistry, Japan

Correspondence to: Professor T Nakamura, Department of Radiology and Cancer Biology, Nagasaki University School of Dentistry, 1-7-1

Sakamoto, Nagasaki 852-8588, Japan; taku@net.nagasaki-u.ac.jp

Accepted 4 August 2003

\section{REFERENCES}

1 Izumi M, Eguchi K, Nakamura H, Takagi Y, Kawabe Y, Nakamura T. Corticosteroid irrigation of parotid gland for treatment of xerostomia in patients with Sïgren's syndrome. Ann Rheum Dis 1998;57:464-9.

2 Petrone D, Condemi JJ, Fife R, Gluck O, Cohen S, Dalgin P. A double-blind, randomized, placebo-controlled study of cevimeline in patients with Siögren's syndrome with xerostomia and keratoconjunctivitis sicca. Arthritis Rheum 2002:46:748-54.

3 Fox RI, Robinson CA, Curd JG, Kozin F, Howell FV. Sjögren's syndrome: proposed criteria for classification. Arthritis Rheum 1986;29:577-85.

Table 1 Effects of cevimeline gargle in patients with Sjögren's syndrome

\begin{tabular}{|c|c|c|c|c|c|c|}
\hline \multirow[b]{3}{*}{ Patients* } & \multirow[b]{3}{*}{ Age } & \multirow[b]{3}{*}{ Sex } & \multicolumn{4}{|c|}{ Saxon test (g/2 min) } \\
\hline & & & \multicolumn{2}{|c|}{ Corticosteroid irrigation $†$} & \multirow{2}{*}{$\begin{array}{l}\text { After cevimeline gargle } \\
\text { (\% increase) }\end{array}$} & \multirow{2}{*}{$\begin{array}{l}\text { Improvement in dry } \\
\text { mouth } \ddagger\end{array}$} \\
\hline & & & Before & After & & \\
\hline 1 & 73 & $\mathrm{~F}$ & 0.33 & 0.16 & $0.45(181)$ & $(+)$ \\
\hline 2 & 61 & $\mathrm{~F}$ & 0.58 & 0.12 & $0.45(275)$ & $i+1$ \\
\hline 3 & 71 & $\mathrm{~F}$ & 1.80 & 1.60 & $1.81(13)$ & $(++)$ \\
\hline 4 & 58 & $\mathrm{~F}$ & 0.40 & 0.10 & $0.06(-40)$ & $i-1$ \\
\hline 5 & 38 & $\mathrm{~F}$ & 0.62 & 0.14 & $0.17(21)$ & $i-j$ \\
\hline
\end{tabular}

*These patients with Sjögren's syndrome were refractory to corticosteroid irrigation; †corticosteroid irrigation was performed as described previously'; †judged by verbal inquiry after cevimeline gargle. 